\title{
Pipeline flow diversion of ruptured blister aneurysms of the supraclinoid carotid artery using a single-device strategy
}

\author{
Robert W. Ryan, MD, Amir S. Khan, MD, Rebecca Barco, BSN, SCRN, and Armen Choulakian, MD \\ Department of Neurosurgery, UCSF Fresno, California
}

OBJECTIVE Ruptured blister aneurysms remain challenging lesions for treatment due to their broad, shallow anatomy and thin, fragile wall. Historical challenges with both open microsurgical approaches and intrasaccular endovascular approaches have led to increased use of flow diversion for management of these aneurysms. However, the optimum paradigm, including timing of treatment, use of dual antiplatelet therapy, and number of flow-diverter devices to use remains unknown. The authors describe their experience with ruptured blister aneurysms treated with flow diversion at their institution, and discuss rates of rebleeding and number of devices used.

METHODS All patients presenting with subarachnoid hemorrhage from a ruptured blister aneurysm and treated with Pipeline flow diversion were identified. Patient demographic data, clinical status and course, need for external ventricular drain (EVD), timing of treatment, and angiographic details and follow-up were recorded.

RESULTS There were 13 patients identified (11 women and 2 men), and 4 had multiple aneurysms. Two aneurysms were treated on initial angiography, with average time to treatment of 3.1 days for the remainder, after discussion with the family and institution of dual antiplatelet therapy. Device placement was technically successful in all patients, with 2 patients receiving 2 devices and the remainder receiving 1 device. There was 1 intraoperative complication, of a wire perforation causing intracerebral hemorrhage requiring decompressive craniectomy. Three patients had required EVD placement for management of hydrocephalus. There was no rebleeding from the target lesion; however, one patient had worsening intraventricular hemorrhage and another had rupture of an unrecognized additional aneurysm, and both died. Of the other 11 patients, 10 made a good recovery, with 1 remaining in a vegetative state. Nine underwent follow-up angiography, with 5 achieving complete occlusion, 2 with reduced aneurysm size, and 2 requiring retreatment for aneurysm persistence or enlargement. There were no episodes of delayed rupture.

CONCLUSIONS Pipeline flow diversion is a technically feasible and effective treatment for ruptured blister aneurysms, particularly in good-grade patients without hydrocephalus. Patients with a worse grade on presentation and requiring EVDs may have higher risk for bleeding complications and poor outcome. There was no rebleeding from the target lesion with use of a single device in this series.

https://thejns.org/doi/abs/10.3171/2017.3.FOCUS1757

KEY WORDS blister aneurysm; subarachnoid hemorrhage; flow diversion; Pipeline embolization device

$\mathrm{R}$ UPTURED blister aneurysms, also known as blood blister-like aneurysms, are a rare subtype, representing approximately $1 \%-2 \%$ of aneurysmal subarachnoid hemorrhage (SAH). ${ }^{15,20,22}$ These broad, shallow lesions occur at the artery sidewall, as opposed to branching points seen with typical saccular aneurysms, and are most often located on the supraclinoid internal carotid artery (ICA), but have also been described at anterior ce- rebral artery and middle cerebral artery locations. ${ }^{24,27}$ Reconstructive techniques, such as attempts at direct surgical clipping, often result in tearing a hole in the artery, whereas attempts at endovascular coiling can lead to puncture of the wall. Indirect surgical repair, such as use of encircling clips, or wrapping and clipping, has been described with numerous technical variations, but the long-term followup of these techniques is uncertain, because they do not

ABBREVIATIONS CTA = CT angiography; EVD = external ventricular drain; ICA = internal carotid artery; ICH = intracerebral hemorrhage; $P E D=$ Pipeline embolization device; $\mathrm{SAH}=$ subarachnoid hemorrhage. 
address the underlying diseased vessel wall. ${ }^{10,16,28}$ To avoid direct treatment of the dome, deconstructive strategies were often used in the past, including vessel trapping or occlusion by surgical or endovascular methods..$^{11,26}$ The risk of stroke is significant in such patients, even with successful balloon test occlusion or high-flow bypass, and risk of aneurysm recurrence further along the diseased vessel wall remains.

Flow-diverter technology offers a very promising approach for management of blister aneurysms, because it provides an endoluminal reconstruction that does not require direct intervention on the weak blister dome. Several small series have examined the use of both the Silk stent and the Pipeline embolization device (PED) for treatment of blister aneurysms, with encouraging results. ${ }^{1,3,5,7,12,17,31}$ The PED is currently available and FDA approved for use in unruptured ICA segment aneurysms, and has significant evidence for efficacy in these lesions. ${ }^{2,23}$ However, use for treatment of ruptured aneurysms is less studied, and numerous issues arise, including timing and use of antiplatelet medications, treatment of hydrocephalus and external ventricular drain (EVD) management, and the risk of rebleeding if an aneurysm is not fully occluded by the device. This latter point has led some authors to advocate up-front use of multiple overlapping devices, to ensure rapid aneurysm occlusion. ${ }^{9}$ Although this may prevent rebleeding from the aneurysm, it also increases the technical difficulty of the case and the possibility of wirerelated complications, as well as the risk of small-vessel occlusion or thromboembolic events. Finally, the optimum timing of treatment of ruptured blister aneurysms remains uncertain, because their natural history is not known with certainty, and the risks of early treatment must be balanced against optimizing antiplatelet strategies and EVD management.

We report our experience with the use of PEDs for treatment of ruptured blister aneurysms and consider patient grade, need for EVD, use of dual antiplatelet therapy, and timing of the procedure.

\section{Methods \\ Patient Population}

This was a retrospective review of all patients who presented to our institution between October 2013 and November 2016 with SAH from a ruptured blister aneurysm and who were treated with the PED. Blister aneurysms were defined as small lesions occurring on the sidewall of the ICA at nonbranching sites, and having dome width equal to or greater than its height. Patient demographic data, including Hunt and Hess clinical grade, aneurysm characteristics, and treatment details were recorded. Clinical course, timing of treatment, and follow-up imaging were assessed. The need for EVD and subsequent shunting, as well as the antiplatelet strategy used, were also determined.

\section{Endovascular Procedure}

All procedures were performed in a hybrid operating room after induction of general anesthesia. Femoral access and triaxial support was used for all cases, with a long sheath such as NeuronMax 088 (Penumbra, Inc.), intermediate catheter such as Navien 058 (Medtronic, Inc.), and delivery microcatheter such as Phenom or Marksman 027 (Medtronic, Inc.). Patients underwent preloading with $650 \mathrm{mg}$ aspirin and $600 \mathrm{mg}$ clopidogrel 6 hours before the procedure, levels of activity were confirmed with point-ofcare testing (VerifyNow; Accumetrics), and then patients received systemic heparinization targeted to an activated clotting time of 250-300 seconds. All patients underwent 3D rotational angiograms to confirm aneurysm size and location, and plan flow-diverter placement. Delivery of the PED was performed under fluoroscopic guidance and confirmed with angiography and contrast-enhanced Dyna CT scans. The need for placement of multiple devices was at the discretion of the treating doctor. Patients were monitored postoperatively in the neurocritical care unit, and blood pressure was maintained below $140 \mathrm{~mm} \mathrm{Hg}$ systolic unless they developed signs of vasospasm or delayed cerebral ischemia, and all received standard postsubarachnoid care.

\section{Clinical and Imaging Follow-Up}

Patients were monitored for clinical signs of delayed cerebral ischemia and received daily transcranial Doppler monitoring. They also underwent Day 7 CT angiography (CTA) follow-up for radiographic vasospasm monitoring. Patients were discharged from neurocritical care and subsequently from the hospital when clinical criteria were met, typically between Days 10 and 14 posttreatment. They were scheduled for follow-up diagnostic angiography between 6 weeks and 3 months after treatment, and then again between 6 and 12 months later.

\section{Results}

There were 13 patients (11 women and 2 men) identified, average age 54.8 years (range $22-71$ years) with $\mathrm{SAH}$ from ruptured blister aneurysms. Location was 8 left ICA and 5 right ICA; 3 patients had multiple aneurysms. Aneurysm size ranged from $1 \times 1 \mathrm{~mm}$ to $3 \times 1 \mathrm{~mm}$. See Table 1 for full demographic details.

Two patients underwent treatment during their initial catheter angiogram study. The remainder were returned to the neurocritical care unit after the initial study, for further discussion of flow diversion, loading of antiplatelet medications, and observation for development of hydrocephalus; these patients underwent PED treatment an average of 3.1 days later (range 1-5 days). Device delivery was successful in all patients, with 2 patients receiving 2 devices and the remainder receiving 1 device. No thromboembolic complications were noted. One patient had a hemorrhagic complication as a result of wire perforation during repositioning for placement of a second PED, and this individual required reversal of anticoagulation and antiplatelets, and decompressive craniectomy as well as placement of an EVD. A second patient had delayed bleeding 10 days after treatment, was found to have a previously unseen third aneurysm of his right posterior inferior cerebellar artery, and died of effects of the rehemorrhage; he had an EVD in place with no related hemorrhage. A third patient, who was Hunt and Hess Grade V on presentation, had worsen- 
TABLE 1. Demographic data in 13 patients with ruptured blister aneurysms

\begin{tabular}{|c|c|c|c|c|c|c|}
\hline $\begin{array}{l}\text { Case } \\
\text { No. }\end{array}$ & $\begin{array}{l}\text { Age } \\
\text { (yrs) }\end{array}$ & Sex & Location & Size & $\begin{array}{l}\mathrm{H} \& \mathrm{H} \\
\text { Grade }\end{array}$ & $\begin{array}{l}\text { Days to } \\
\text { Treatment }\end{array}$ \\
\hline 1 & 55 & $\mathrm{~F}$ & Lt ICA & $1 \mathrm{~mm}$ & II & 3 \\
\hline 2 & 44 & $\mathrm{~F}$ & Lt ICA & $3 \mathrm{~mm} \times 1.5 \mathrm{~mm}$ & I & 3 \\
\hline 3 & 64 & M & Lt ICA & $2.5 \mathrm{~mm} \times 1.5 \mathrm{~mm}$ & III & 3 \\
\hline 4 & 71 & $\mathrm{~F}$ & Rt ICA $\times 2$ & $1.5 \mathrm{~mm} \& 1.5 \mathrm{~mm}$ & II & 3 \\
\hline 5 & 62 & M & Lt ICA x 2 & $\begin{array}{l}2.5 \mathrm{~mm} \times 2.5 \mathrm{~mm} \\
\& 2 \mathrm{~mm} \times 2 \mathrm{~mm}\end{array}$ & III & 4 \\
\hline 6 & 40 & $\mathrm{~F}$ & Rt ICA & $2.5 \mathrm{~mm} \times 2 \mathrm{~mm}$ & II & 0 \\
\hline 7 & 58 & $\mathrm{~F}$ & Lt ICA $\times 2$ & $2 \mathrm{~mm} \& 2 \mathrm{~mm}$ & IV & 2 \\
\hline 8 & 58 & $\mathrm{~F}$ & Rt ICA & $3 \mathrm{~mm} \times 1 \mathrm{~mm}$ & II & 1 \\
\hline 9 & 71 & $\mathrm{~F}$ & Lt ICA & $<1 \mathrm{~mm}$ & V & 2 \\
\hline 10 & 69 & $\mathrm{~F}$ & Lt ICA & $1.5 \mathrm{~mm} \times 1 \mathrm{~mm}$ & I & 3 \\
\hline 11 & 22 & $\mathrm{~F}$ & Lt ICA & $2 \mathrm{~mm} \times 2 \mathrm{~mm}$ & II & 0 \\
\hline 12 & 47 & $\mathrm{~F}$ & Rt ICA & $2 \mathrm{~mm} \times 1 \mathrm{~mm}$ & II & 5 \\
\hline 13 & 52 & $F$ & Rt ICA & $1.5 \mathrm{~mm} \times 1.5 \mathrm{~mm}$ & I & 5 \\
\hline
\end{tabular}

$\mathrm{H} \& \mathrm{H}=$ Hunt and Hess.

ing intraventricular hemorrhage after her procedure, with an EVD already in place, and showed no signs of clinical improvement; she received comfort care from her family and later died. The remaining 10 patients made a satisfactory neurological recovery (Table 2).

During the inpatient and outpatient follow-up period, no events of rebleeding from the treated aneurysms have been identified. Nine patients have undergone diagnostic cerebral angiograms for follow-up, 1 has undergone CTA follow-up only, and 1 has imaging pending. Five patients $(56 \%)$ had complete occlusion of their aneurysms at 3-month follow-up-2 (22\%) had ongoing filling but reduced size of their aneurysms and planned for further follow-up imaging; 1 had persistent filling at 12-month follow-up and underwent retreatment with a second PED; and 1 had enlargement of the aneurysm at initial 4-month follow-up and underwent retreatment with a second PED. The patient with only CTA follow-up had no evidence of ongoing filling on that scan. No patients developed new neurological deficits during follow-up.

\section{Illustrative Cases \\ Case 2}

This 44-year-old woman presented with sudden onset of severe headache (Hunt and Hess Grade I), and a head CT demonstrated SAH primarily in the left sylvian fissure (Fisher Grade 2) (Fig. 1). A CTA study of the head raised suspicion for a small left supraclinoid ICA aneurysm. The patient underwent diagnostic cerebral angiography, which demonstrated a $3 \times 1.5-\mathrm{mm}$ left supraclinoid ICA blister aneurysm that was too small, shallow, and wide necked for intrasaccular treatment. She underwent loading with dual antiplatelet therapy according to the protocol previously described, and 2 days later underwent embolization of the aneurysm using the PED. Intraprocedural dissection of the left petrous ICA occurred, requiring placement of an Enterprise stent in the region of dissection. One-week follow-up cerebral angiography was performed during her hospital stay, and showed no significant change in the aneurysm. She was eventually discharged home in good condition. The 3-month follow-up cerebral angiogram showed interval occlusion of the aneurysm, and the 1-year followup cerebral angiogram showed no aneurysm recurrence, as did an 18-month follow-up CTA.

\section{Case 4}

This 71-year-old woman presented with sudden onset of severe headache (Hunt and Hess Grade II), and a head CT demonstrated right-sided SAH in the basal cisterns

TABLE 2. Outcomes in 13 patients with ruptured blister aneurysms

\begin{tabular}{|c|c|c|c|c|c|c|}
\hline $\begin{array}{l}\text { Case } \\
\text { No. }\end{array}$ & $\begin{array}{l}\text { No. of } \\
\text { Devices }\end{array}$ & $\begin{array}{c}\text { Aneurysm } \\
\text { Occluded on Day } \\
\text { of Treatment }\end{array}$ & $\begin{array}{c}\text { Aneurysm } \\
\text { Occluded on } \\
\text { Imaging Follow-Up }\end{array}$ & $\begin{array}{c}\text { Rehemorrhage } \\
\text { From Treated } \\
\text { Aneurysm }\end{array}$ & $\begin{array}{l}\mathrm{mRS} \\
\text { Score }\end{array}$ & Complications \\
\hline 1 & 1 & No & Yes & No & 0 & None \\
\hline 2 & 1 & No & Yes & No & 0 & Dissection of petrous ICA requiring Enterprise stent \\
\hline 3 & 1 & No & Yes & No & 1 & None \\
\hline 4 & 1 & No & No & No & 1 & None \\
\hline 5 & 1 & No & No & No & 6 & Death secondary to rehemorrhage from untreated 3rd aneurysm \\
\hline 6 & 1 & No & No & No & 0 & None \\
\hline 7 & 1 & No & No & No & 2 & None \\
\hline 8 & 1 & No & No & No & 1 & Lt SMA infarction during diagnostic angiogram \\
\hline 9 & 1 & No & No & No & 6 & Death secondary to preprocedural rerupture \\
\hline 10 & 1 & No & No & No & 1 & None \\
\hline 11 & 2 & No & Yes & No & 0 & None \\
\hline 12 & 2 & No & Yes & No & 5 & $\begin{array}{l}\text { Intraprocedural hemorrhage requiring hemicraniectomy \& } \\
\text { intracerebral hematoma evacuation }\end{array}$ \\
\hline 13 & 1 & No & TBD & No & 1 & None \\
\hline
\end{tabular}

$\mathrm{mRS}=$ modified Rankin Scale; $\mathrm{SMA}=$ supplementary motor area; $\mathrm{TBD}=$ to be determined . 

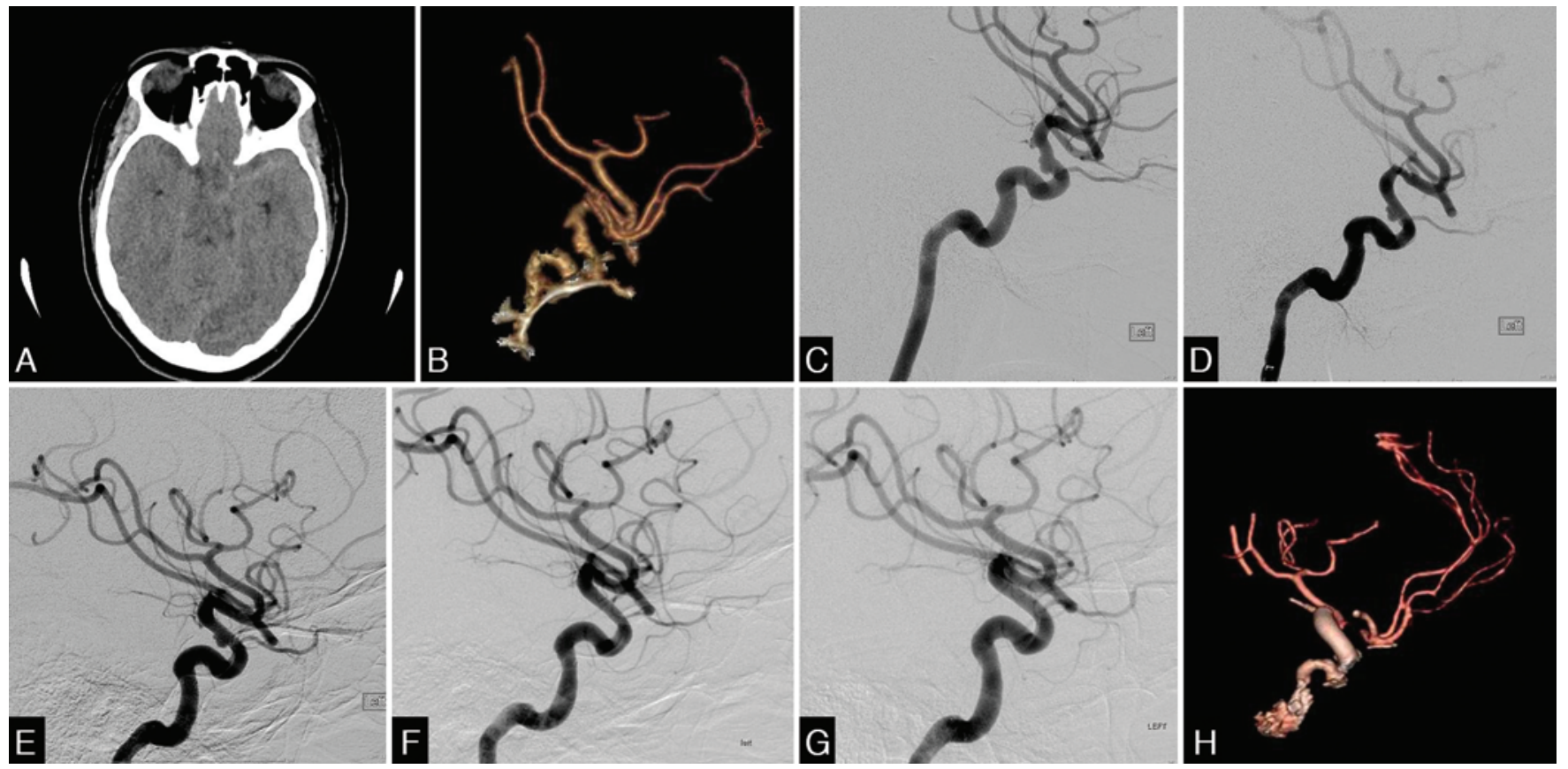

FIG. 1. Case 2. Noncontrast head CT demonstrating SAH in the left sylvian fissure (A). A CTA study of the head raised suspicion for a left supraclinoid ICA blister aneurysm (B). Cerebral angiograms obtained immediately pre- (C) and posttreatment (D) of a $3 \times$ 1.5-mm left supraclinoid ICA blister aneurysm treated with the PED. One-week follow-up cerebral angiogram showing no change in the treated aneurysm (E). Three-month follow-up cerebral angiogram demonstrating interval occlusion of the aneurysm (F). One-year follow-up cerebral angiogram $(\mathbf{G})$ and 18-month follow-up CTA $(\mathbf{H})$ showing persistent occlusion of the aneurysm.

and sylvian fissure (Fisher Grade 2) (Fig. 2). A CTA study of the head failed to demonstrate cerebrovascular pathology that would have caused the hemorrhage. Of note, the patient had an MR angiogram of the head performed 4 years previously for workup of diplopia; that study was also negative for cerebrovascular pathology. The patient underwent diagnostic cerebral angiography, which demonstrated 2 right-sided superior hypophyseal artery blis-
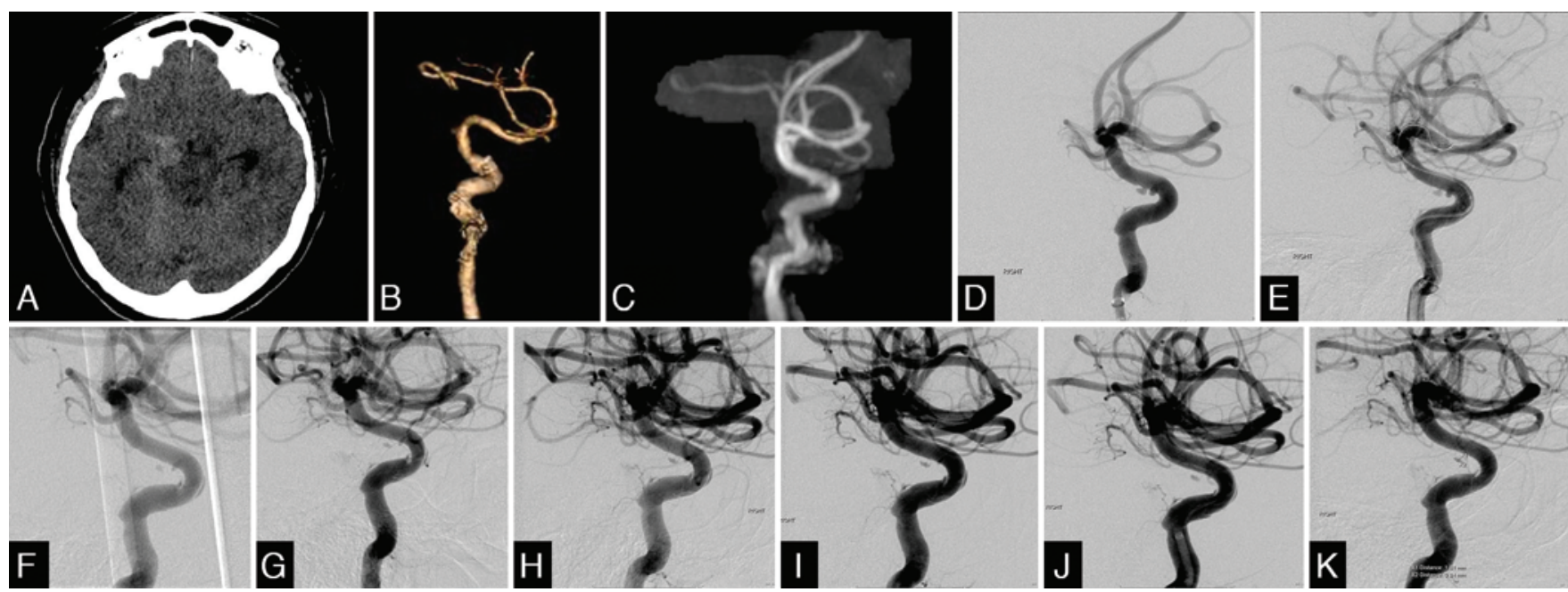

FIG. 2. Case 4. Noncontrast head CT demonstrating right-sided SAH in the basal cisterns and sylvian fissure (A). A CTA study of the head negative for causative pathology (B). An MR angiogram of the head from 4 years prior, which is also negative (C). Cerebral angiograms obtained immediately pre- (D) and posttreatment (E) of 2 right-sided superior hypophyseal artery blister aneurysms measuring $1.5 \mathrm{~mm}$ each, treated with the PED. Three-month follow-up cerebral angiogram showing endoleak at the proximal aspect of the PED, with delayed filling of both aneurysms, but with contrast stagnation (F). Six-month (G), 1-year $(\mathbf{H})$, and 15-month (I) follow-up cerebral angiograms showed no interval occlusion of the aneurysms. Cerebral angiogram obtained immediately after retreatment of the aneurysms with a Pipeline Flex embolization device (J). Six-month follow-up cerebral angiogram obtained after retreatment demonstrating interval occlusion of the proximal aneurysm, with continued delayed filling of the distal aneurysm (K). 


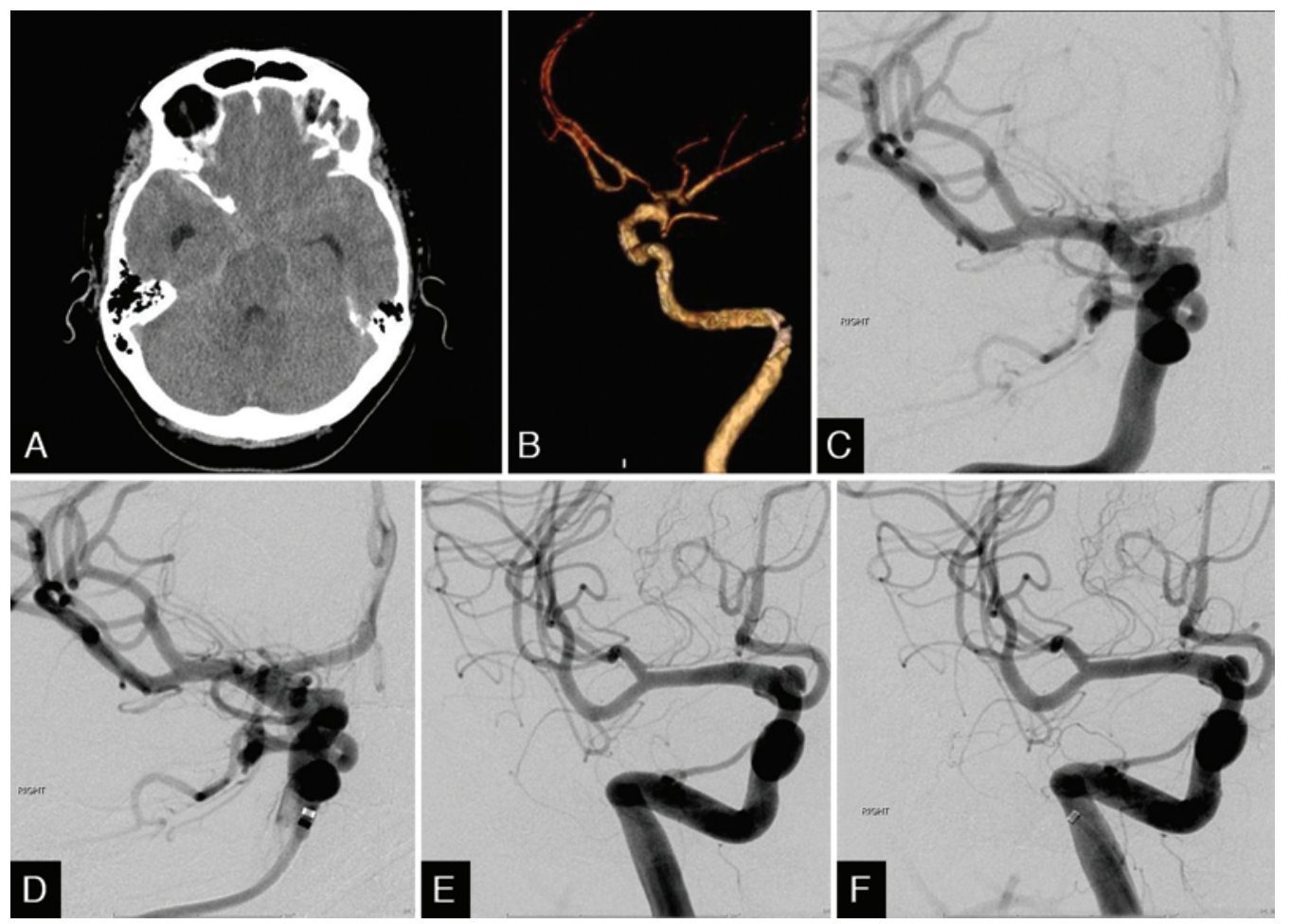

FIG. 3. Case 8. Noncontrast head CT demonstrating diffuse SAH (A). A CTA study of the head negative for causative pathology (B). Cerebral angiograms obtained immediately pre- (C) and posttreatment (D) of a $3 \times 1-\mathrm{mm}$ dorsal right ICA blister aneurysm treated with the Pipeline Flex embolization device. Three-month follow-up cerebral angiogram showing interval growth of the treated aneurysm to $4.5 \times 2-\mathrm{mm}(\mathrm{E})$. Cerebral angiogram obtained immediately after retreatment of the aneurysm with another Pipeline Flex embolization device (F).

ter aneurysms measuring $1.5 \mathrm{~mm}$ each. These aneurysms were too small for intrasaccular treatment. She underwent loading with dual antiplatelet therapy per the protocol previously described, and 3 days later underwent embolization of the aneurysms using the PED. She was eventually discharged home in good condition. Her 3-month followup cerebral angiogram showed endoleak at the proximal aspect of the Pipeline with delayed filling of both aneurysms, but with contrast stagnation. Six-month, 1-year, and 15-month follow-up cerebral angiograms showed no interval occlusion of the aneurysms, and the patient subsequently underwent retreatment of the lesions with placement of a Pipeline Flex embolization device. A 6-month follow-up cerebral angiogram after retreatment demonstrated interval occlusion of the proximal aneurysm, with continued delayed filling of the distal aneurysm.

\section{Case 8}

This 58-year-old woman presented with sudden onset of severe headache (Hunt and Hess Grade II), and a head CT demonstrated diffuse SAH (Fisher Grade 2) (Fig. 3). A CTA study of the head failed to demonstrate cerebrovascular pathology that would have caused the hemorrhage. The patient underwent diagnostic cerebral angiography, which demonstrated a $3 \times 1-\mathrm{mm}$ dorsal right ICA blister aneurysm, along with a $2.5 \times 1-\mathrm{mm}$ right posterior communicating artery infundibulum and a $2 \times 1-\mathrm{mm}$ left posterior communicating artery infundibulum. The ruptured lesion was thought to be the dorsal right ICA blister an- eurysm given its size and shape; however, this lesion was too small, shallow, and wide necked for intrasaccular treatment. Following angiography the patient was noted to have $3 / 5$ right upper-extremity weakness, and an MRI view of the brain showed a small area of acute infarction in the left supplementary motor cortex. She underwent loading with dual antiplatelet therapy per the protocol previously described, and 2 days later she underwent uncomplicated embolization of the dorsal right ICA blister aneurysm with the Pipeline Flex embolization device. She was eventually discharged home in good condition, with improvement in her right upper-extremity weakness to only minimal weakness of her right hand. Three months later the patient underwent follow-up cerebral angiography, which showed that the treated aneurysm had grown to $4.5 \times 2 \mathrm{~mm}$, and a second Pipeline Flex was placed at that time.

\section{Discussion}

Treatment of ruptured blister aneurysms with the PED was technically feasible in all patients in our series and led to good neurological outcomes in $77 \%$ of patients, with no episodes of procedural or delayed aneurysmal rebleeding. One patient suffered a procedural complication of an intracranial vessel microwire perforation, with associated SAH and intracerebral hemorrhage (ICH) necessitating surgical decompressive craniectomy. A majority of treated patients achieved either complete aneurysm occlusion or reduction in size on follow-up imaging. Retreatment with placement 
of an additional flow diverter was performed in 2 patients after delayed follow-up diagnostic angiography demonstrated persistence or enlargement of the treated blister aneurysms.

Ruptured blister aneurysms have been historically challenging to effectively treat with open surgical or endovascular methods, largely due to the diminutive dome size and absence of a true aneurysm neck to facilitate successful aneurysm occlusion with microsurgical clip ligation or endovascular coil occlusion. Open surgical microsurgical clipping approaches have largely fallen out of favor due to a significant incidence of severe operative complications. Ogawa et al. described an operative aneurysmal rerupture risk of 38\% with direct aneurysm clipping, aneurysmal segment trapping, or aneurysm wrapping. Of this operative rerupture cohort, only $13 \%$ had good clinical outcomes, and $53 \%$ died as a result of surgery. ${ }^{24}$ Other single-center series of open surgical management of ruptured blister aneurysms reported $55 \%$ and $41 \%$ operative rerupture rates, respectively. ${ }^{20,25}$ High rates of open surgical approaches are probably due to the pseudoaneurysmal thin-walled nature of blister aneurysms, which have been reported to lack tunica media and internal elastic lamina. ${ }^{8,24} \mathrm{~A}$ meta-analysis including endovascular deconstructive parent-vessel occlusion treatment of ruptured blister aneurysms found a significantly higher procedural ischemic infarct complication of $29 \%$, versus only $5 \%$ for endovascular reconstructive approaches with flow diverters or for other endovascular methods, including stent-assisted coil occlusion, balloonassisted coil occlusion, or overlapping placement of traditional (i.e., nonflow-diverter) intracranial stents, with similar rates of perioperative morbidity and long-term good outcomes. ${ }^{29}$

Ours is the largest single-center experience of PED treatment of ruptured blister aneurysms to date, and adds to the similar experience of other centers with regard to overall good clinical outcomes and relatively low procedural risk. One recent 10-patient, 2-center case series by Linfante et al. described a $90 \%$ good clinical outcome rate with no procedural complications and no aneurysmal reruptures. ${ }^{17} \mathrm{~A}$ 12-patient multicenter series of PEDs in ruptured ICA blister aneurysms by Yoon et al. reported an $83 \%$ rate of good clinical outcomes, and no procedural or postflow-diversion aneurysmal rerupture. ${ }^{31}$ Of 62 ruptured blister aneurysms treated with flow diversion in a recent meta-analysis, $86 \%$ achieved good clinical outcomes, and $17 \%$ suffered procedural complications including an almost $8 \%$ risk of procedural ICH. ${ }^{29} \mathrm{~A}$ single-center series published by Chalouhi et al. reported PED treatment of 8 total blister aneurysms, of which 5 were ruptured and 1 was discovered during patient presentation with sentinel headache: the authors reported $100 \%$ good clinical outcome on follow-up, with no procedural complications and no aneurysmal reruptures. ${ }^{3}$ Çinar et al. published a 7-patient ruptured blister aneurysm series with PED treatment and reported good clinical outcome in $71 \%$ and no procedural or postprocedural aneurysm rerupture. ${ }^{4} \mathrm{~A}$ series of 11 ruptured blister aneurysm cases treated with the Silk flow diverter reported good clinical outcomes in $92 \%$, no aneurysmal reruptures, and a procedural minor ischemic stroke in 1 case. $^{1}$
A challenging aspect of flow-diversion treatment of ruptured blister aneurysms is the necessity of concomitant dual antiplatelet therapy to minimize the risk of device thrombosis. However, this can complicate the inpatient management of attendant procedures for patients with SAH, especially EVD placement and removal, shunt placement, and decompressive craniectomy. Ventriculoperitoneal shunt-related ICH rates of up to $71 \%$ have been reported in patients concomitantly treated with dual antiplatelet agents after stent-assisted aneurysm coiling, ${ }^{13,18}$ and a significantly increased risk of fatal hemorrhagic complications was reported with respect to dual antiplatelet therapy during stent-assisted aneurysm coiling by Mocco et al., who found a $12 \%$ risk of mortality in an SAH cohort relative to a $0.8 \%$ mortality in the unruptured aneurysm cohort. ${ }^{21}$ All previously reported blister aneurysm flow-diversion treatment series described dual antiplatelet pretreatment prior to flow-diverter placement; similarly, all patients in our series also underwent preloading with aspirin and clopidogrel. In 1 case, intraprocedural wire perforation causing SAH and ICH occurred, and the patient was transfused with platelets and reversal of heparin anticoagulation, followed by surgical hematoma evacuation and decompressive craniectomy. Due to the significant hemorrhagic complication, antiplatelet agents were withheld, yet interestingly, during follow-up inpatient cerebral angiography performed 4 days later, the Pipeline device demonstrated patency without any signs of thrombosis. In 2 other patients, an EVD was placed prior to preloading with dual antiplatelets, and no ventriculostomy-related hemorrhage was observed. Both patients died of complications unrelated to ventriculostomy hemorrhage, although in 1 patient the ventriculostomy was removed without hemorrhagic complication.

In 11 of the 13 patients in our series, only a single PED was placed; in 1 other case a second overlapping flow diverter was placed after the intended single device placement resulted in unsatisfactory lesion coverage due to device foreshortening. Single device placement occurred in the majority of reported case series, ${ }^{1,3,4,17,29,31}$ although aneurysmal rerupture in a patient who had recently undergone flow diversion while receiving dual antiplatelet agents has been reported. ${ }^{19}$ Therefore, current practice strategies for ruptured blister aneurysms also include placement of multiple telescoped overlapping flow diverters to minimize the risk of postdiversion rerupture and to speed parent vessel endothelialization and exclusion of the lesion. Although this appears to be an elegant solution to the potential problem of postdiversion rerupture, a significant reduction in posttreatment rerupture has not been demonstrated to date. Lang et al. recently reported a single case of 9-month recurrence of a ruptured supraclinoid ICA aneurysm despite initial treatment with 2 overlapping flow diverters, with the authors placing a third flow diverter after discovery of the recurrence. ${ }^{14}$ Additionally, the increased number of devices may contribute to risks of cerebral or ophthalmic ischemia due to jailing of perforating vessels, increased risks of device thrombosis, or procedural complications related to the additional steps required for placement of multiple flow diverters. ${ }^{1,31}$ In our own series, the single operative complication of SAH and 
ICH from intracranial artery wire perforation occurred during placement of a second overlapping PED.

A related issue is the necessity of additional flow-diverter placement if lesions are completely or partially persistent during follow-up cerebral angiography. In our series an additional device was placed in 2 cases: in the first the lesion partially persisted after 12-month angiography, leading to placement of a second device telescoped within the previous one, with persistence of the lesion on 6-month angiography thereafter. In the second case, follow-up angiography performed 4 months after initial treatment demonstrated enlargement of the lesion: a second device was telescoped within the previous device and follow-up angiography is pending. Although significant reduction of arterial pulsatile flow into the blister aneurysm dome probably is protective, reports of postdiversion rerupture highly suggest that complete obliteration of the lesion is preferable. Further data are needed regarding the optimal time for placement of additional flow diverters for residual blister lesions.

It has been our group's practice with regard to the PED in general to discontinue dual antiplatelet therapy in favor of monotherapy after 6-month angiography-such a strategy might expedite thrombosis of residual lesions. The ideal antiplatelet regimen following PED placement is not clearly established and varies by proceduralist. One recent meta-analysis of 19 published series of PED-treated patients suggested increased symptomatic thrombotic ischemic events in patients treated with $\leq 6$ months of clopidogrel, and fewer thrombotic and hemorrhagic events in patients treated with $>6$ months of $\geq 300 \mathrm{mg}$ of concomitant aspirin. ${ }^{30}$ Additional data are needed to establish the relationship of varying antiplatelet regimens to occlusion of flow-diverted, ruptured blister aneurysms. Conversely, additional clinical data regarding the safety of temporary cessation and reversal or minimization of dual antiplatelet therapies in the setting of post-PED hemorrhagic complications need to be further ascertained. Coming improvements in flow-diverter technologies may obviate or minimize the need for antiplatelet therapies in patients treated with PEDs. ${ }^{6}$

The results of our series are limited by the modest total number of treated ruptured blister aneurysms and restriction to the clinical practices of a single medical center. Additionally, although our results support the plausibility of a single flow-diverter strategy for treatment of ruptured blister aneurysms, there is insufficient evidence to comment on the superiority (or lack thereof) of this method compared with a multiple flow-diverter strategy.

\section{Conclusions}

Endovascular flow diversion of ruptured intracranial blister aneurysms is a treatment that is increasingly practiced for this difficult SAH etiology. Our results add to previous reports that demonstrate reasonable procedural safety, good patient clinical outcomes, and low risk of aneurysmal rerupture following flow diversion. Use of a single flow-diverting device appears to be a reasonable treatment strategy, but longer-term clinical data comparing outcomes with single- versus multiple-device diversion is needed.

\section{References}

1. Aydin K, Arat A, Sencer S, Hakyemez B, Barburoglu M, Sencer A, et al: Treatment of ruptured blood blister-like aneurysms with flow diverter SILK stents. J Neurointerv Surg 7:202-209, 2015

2. Becske T, Kallmes DF, Saatci I, McDougall CG, Szikora I, Lanzino G, et al: Pipeline for uncoilable or failed aneurysms: results from a multicenter clinical trial. Radiology 267:858868,2013

3. Chalouhi N, Zanaty M, Tjoumakaris S, Gonzalez LF, Hasan D, Kung D, et al: Treatment of blister-like aneurysms with the Pipeline Embolization Device. Neurosurgery 74:527532,2014

4. Çinar C, Oran İ, Bozkaya H, Ozgiray E: Endovascular treatment of ruptured blister-like aneurysms with special reference to the flow-diverting strategy. Neuroradiology 55:441447,2013

5. Cruz JP, O'Kelly C, Kelly M, Wong JH, Alshaya W, Martin $\mathrm{A}$, et al: Pipeline Embolization Device in aneurysmal subarachnoid hemorrhage. AJNR Am J Neuroradiol 34:271276, 2013

6. Hagen MW, Girdhar G, Wainwright J, Hinds MT: Thrombogenicity of flow diverters in an ex vivo shunt model: effect of phosphorylcholine surface modification. J Neurointerv Surg [epub ahead of print], 2016

7. Hu YC, Chugh C, Mehta H, Stiefel MF: Early angiographic occlusion of ruptured blister aneurysms of the internal carotid artery using the Pipeline Embolization Device as a primary treatment option. J Neurointerv Surg 6:740-743, 2014

8. Ishikawa T, Nakamura N, Houkin K, Nomura M: Pathological consideration of a "blister-like" aneurysm at the superior wall of the internal carotid artery: case report. Neurosurgery 40:403-406, 1997

9. Kabbasch C, Mpotsaris A, Behme D, Dorn F, Stavrinou P, Liebig T: Pipeline Embolization Device for treatment of intracranial aneurysms-the more, the better? A single-center retrospective observational study. J Vasc Interv Neurol 9:14-20, 2016

10. Kalani MY, Zabramski JM, Kim LJ, Chowdhry SA, Mendes $\mathrm{GA}$, Nakaji $\mathrm{P}$, et al: Long-term follow-up of blister aneurysms of the internal carotid artery. Neurosurgery 73:1026-1033, 2013

11. Kamijo K, Matsui T: Acute extracranial-intracranial bypass using a radial artery graft along with trapping of a ruptured blood blister-like aneurysm of the internal carotid artery. Clinical article. J Neurosurg 113:781-785, 2010

12. Kulcsár Z, Wetzel SG, Augsburger L, Gruber A, Wanke I, Rüfenacht DA: Effect of flow diversion treatment on very small ruptured aneurysms. Neurosurgery 67:789-793, 2010

13. Kung DK, Policeni BA, Capuano AW, Rossen JD, Jabbour PM, Torner JC, et al: Risk of ventriculostomy-related hemorrhage in patients with acutely ruptured aneurysms treated using stent-assisted coiling. J Neurosurg 114:10211027, 2011

14. Lang ST, Assis Z, Wong JH, Morrish W, Mitha AP: Rapid delayed growth of ruptured supraclinoid blister aneurysm after successful flow diverting stent treatment. J Neurointerv Surg 9:e16, 2017

15. Lee BH, Kim BM, Park MS, Park SI, Chung EC, Suh SH, et al: Reconstructive endovascular treatment of ruptured blood blister-like aneurysms of the internal carotid artery. J Neurosurg 110:431-436, 2009

16. Lee JW, Choi HG, Jung JY, Huh SK, Lee KC: Surgical strategies for ruptured blister-like aneurysms arising from the internal carotid artery: a clinical analysis of 18 consecutive patients. Acta Neurochir (Wien) 151:125-130, 2009

17. Linfante I, Mayich M, Sonig A, Fujimoto J, Siddiqui A, Dabus G: Flow diversion with Pipeline Embolic Device as treatment of subarachnoid hemorrhage secondary to blister aneu- 
rysms: dual-center experience and review of the literature. J Neurointerv Surg 9:29-33, 2017

18. Mahaney KB, Chalouhi N, Viljoen S, Smietana J, Kung DK, Jabbour P, et al: Risk of hemorrhagic complication associated with ventriculoperitoneal shunt placement in aneurysmal subarachnoid hemorrhage patients on dual antiplatelet therapy. J Neurosurg 119:937-942, 2013

19. Mazur MD, Taussky P, MacDonald JD, Park MS: Rerupture of a blister aneurysm after treatment with a single flowdiverting stent. Neurosurgery 79:E634-E638, 2016

20. Meling TR, Sorteberg A, Bakke SJ, Sletteb $\varnothing$ H, Hernesniemi J, Sorteberg W: Blood blister-like aneurysms of the internal carotid artery trunk causing subarachnoid hemorrhage: treatment and outcome. J Neurosurg 108:662-671, 2008

21. Mocco J, Snyder KV, Albuquerque FC, Bendok BR, Alan SB, Carpenter JS, et al: Treatment of intracranial aneurysms with the Enterprise stent: a multicenter registry. J Neurosurg 110:35-39, 2009

22. Nakagawa F, Kobayashi S, Takemae T, Sugita K: Aneurysms protruding from the dorsal wall of the internal carotid artery. J Neurosurg 65:303-308, 1986

23. Nelson PK, Lylyk P, Szikora I, Wetzel SG, Wanke I, Fiorella D: The Pipeline Embolization Device for the intracranial treatment of aneurysms trial. AJNR Am J Neuroradiol 32:34-40, 2011

24. Ogawa A, Suzuki M, Ogasawara K: Aneurysms at nonbranching sites in the surpaclinoid portion of the internal carotid artery: internal carotid artery trunk aneurysms. Neurosurgery 47:578-586, 2000

25. Owen CM, Montemurro N, Lawton MT: Blister aneurysms of the internal carotid artery: microsurgical results and management strategy. Neurosurgery [epub ahead of print], 2016

26. Park JH, Park IS, Han DH, Kim SH, Oh CW, Kim JE, et al: Endovascular treatment of blood blister-like aneurysms of the internal carotid artery. J Neurosurg 106:812-819, 2007

27. Peschillo S, Miscusi M, Caporlingua A, Cannizzaro D, Santoro A, Delfini R, et al: Blister-like aneurysms in atypical locations: a single-center experience and comprehensive literature review. World Neurosurg 84:1070-1079, 2015
28. Regelsberger J, Matschke J, Grzyska U, Ries T, Fiehler J, Köppen J, et al: Blister-like aneurysms - a diagnostic and therapeutic challenge. Neurosurg Rev 34:409-416, 2011

29. Rouchaud A, Brinjikji W, Cloft HJ, Kallmes DF: Endovascular treatment of ruptured blister-like aneurysms: a systematic review and meta-analysis with focus on deconstructive versus reconstructive and flow-diverter treatments. AJNR Am J Neuroradiol 36:2331-2339, 2015

30. Skukalek SL, Winkler AM, Kang J, Dion JE, Cawley CM, Webb A, et al: Effect of antiplatelet therapy and platelet function testing on hemorrhagic and thrombotic complications in patients with cerebral aneurysms treated with the Pipeline Embolization Device: a review and meta-analysis. J Neurointerv Surg 8:58-65, 2016

31. Yoon JW, Siddiqui AH, Dumont TM, Levy EI, Hopkins LN, Lanzino G, et al: Feasibility and safety of Pipeline Embolization Device in patients with ruptured carotid blister aneurysms. Neurosurgery 75:419-429, 2014

\section{Disclosures}

Dr. Ryan is a consultant for Penumbra, Inc.

\section{Author Contributions}

Conception and design: Ryan. Acquisition of data: Ryan, Khan, Choulakian. Analysis and interpretation of data: all authors. Drafting the article: all authors. Critically revising the article: Ryan, Khan, Choulakian. Reviewed submitted version of manuscript: all authors. Approved the final version of the manuscript on behalf of all authors: Ryan.

\section{Correspondence}

Robert Ryan, University Neurosciences Institute, UCSF Fresno, 2335 E Kashian Ln., Ste. 301, Fresno, CA 93701. email: rryan@ ualberta.ca. 